\title{
Servicio de atención al cliente a través de redes sociales para aumentar las ventas
}

\author{
Customer service through social networks to increase sales
}

\begin{tabular}{l|r}
\cline { 2 - 2 } & Andrea Amate \\
\hline $\begin{array}{l}\text { Artículo recibido en enero 2020 } \\
\text { Arbitrado en febrero 2020 } \\
\text { Publicado en mayo 2020 }\end{array}$ & andre3_elizabeth@hotmail.com \\
ORCID: 0000-0001-8865-0478 \\
Universidad de Carabobo, Venezuela
\end{tabular}

RESUMEN

Palabras clave: Esta investigación propone analizar el servicio de atención al cliente a través de redes sociales que permita aumentar las ventas de la empresa Mundo Geylin C.A. Aplicando el método cuantitativo, la investigación es de carácter documental, descriptiva y de campo, aplicacada a una empresa dedicada a la comercialización de piezas y componentes de bisutería para la fabricación de accesorios como pulseras, collares, brazaletes, zarcillos, entre otros, que utiliza principalmente las redes sociales. La población a investigar estuvo conformada por el encargado del servicio de atención al cliente, el gerente general y veintiocho (28) clientes, a quienes se les aplicó un cuestionario. Como resultado se tuvo que la totalidad de los clientes están insatisfechos con las respuestas obtenidas por parte de la empresa, en base a los resultados, lo cual obliga a la empresa a rediseñar sus estrategias y procesos de atención al cliente.

Atención al cliente, cliente, plan de servicios, redes sociales, ventas

ABSTRACT

Keywords:
This research proposes to analyze the customer service through social networks that allows increasing sales of Mundo Geylin C.A. Applying the quantitative method, the research is of a documentary, descriptive and field nature, applied to a company dedicated to the commercialization of jewelery pieces and components for the manufacture of accessories such as bracelets, necklaces, bracelets, earrings, among others, that it uses mainly social networks. The population to be investigated consisted of the person in charge of customer service, the general manager, and twenty-eight (28) customers, who were given a questionnaire. As a result, all the customers were dissatisfied with the responses obtained by the company, based on the results, which forces the company to redesign its customer service strategies and processes.

Customer Support - client - social networks - sales 


\section{INTRODUCCIÓN}

En la segunda década del siglo XXI existe un mundo globalizado, en el cual se ha experimentado un inmenso avance tecnológico, que ha traído consigo cambios en los canales de comunicación, por lo tanto ciertos cambios también en que los clientes interactúan con sus proveedores de bienes 0 servicios, de igual manera el enfoque de las empresas ha variado, antes había un enfoque hacia el producto y el aumento continuo de la producción, de tal manera que existía una visión cerrada, tal como afirma Dvoskin (2004:43) al comentar que a "principios de la década de los 60 del siglo $\mathrm{XX}$, propuso la idea que, a diferencia de lo que se creía en las orientaciones a la producción y a las ventas, no solamente era necesario diseñar y crear el producto", de tal manera se fueron creando otros enfoques tomando en cuenta el cliente y sus preferencias.

Sin embargo, para que un cliente decida adquirir un bien o servicio debe tener una necesidad que cubrir. Uno de los objetivos que tiene conocer al cliente es saber de qué manera a través de la atención prestada en el ofrecimiento del bien o servicio se puede lograr que este lo adquiera. Por otro lado, la atención al cliente se produce como complemento adicional al bien o servicio que se ofrece originalmente una empresa, sea esta comercializadora, o productora, de tal manera Carrasco (2012) define atención al cliente como:
Un servicio añadido que todas las empresas ofrecen a sus clientes, independientemente del sector en el que se encuentren o los bienes que comercialicen. Por otro lado, no existen dos clientes iguales, algunos consideran más importante el trato dispensado, otros valoran más la calidad de las instalaciones o su apariencia. (p.38)

En el orden de las ideas anteriores, se puede afirmar que la atención al cliente forma parte fundamental en la decisión del mismo para la adquisición de un bien o servicio, esto representaría crecimiento o decrecimiento de la empresa. Puesto que para que una empresa pueda ser sostenible en el tiempo debe ser rentable y esto solo se logra a través de la motivación del cliente en continuar adquiriendo el bien o servicio prestado. Asimismo, para satisfacer al cliente externo (adquiriente del bien o servicio), se debe satisfacer en primera estancia al cliente interno (empleados), debido a que el cliente interno es el que se encargará de la atención del cliente externo.

Cabe denotar, que en Venezuela las grandes empresas poseen personal asignado a la ocupación de atender al cliente, tal personal puede encontrarse disponible tanto vía telefónica como web. Dentro de sus funciones están proveer de información al cliente, solución de inquietudes, dudas y quejas de los clientes, como es el caso de NetUno (televisión por cable y otros servicios de telecomunicaciones), que posee una 
cuenta de Twitter destinada a dar información tanto a clientes como aquellas personas que no están suscritas a ningún servicio. Ahora bien, en el caso de los pequeños establecimientos como los minoristas, muchos de ellos carecen de personal que cumplan funciones de servicio de atención al cliente a través de plataformas tecnológicas como las redes sociales, en algunos casos motivado a su imposibilidad de adquirir tecnología adecuada para tal razón y en otros por no contar con personal que tenga algún conocimiento básico en el tema.

La atención al cliente se inicia desde el primer contacto con el cliente, bien sea física, telefónica o digitalmente. A razón de las herramientas tecnológicas que se disfrutan en la actualidad, tales como los teléfonos inteligentes, han innovado la forma de comunicarse, la cual en el presente es a través de plataformas que utilizan internet, como el correo electrónico, webs corporativas, blogs y redes sociales.

Es por ello, que una de las ventajas del uso de este tipo de plataformas para comunicarse con el cliente es la reciprocidad de la información, ya que se puede saber directamente del cliente su criterio acerca del servicio prestado o el producto que se ofrece. En ese mismo sentido la plataforma más usada y que ha tenido mayor crecimiento en los últimos años han sido las redes sociales, tal como lo afirma Aced (2010:5) al mencionar que "Facebook llego a tener cien millones de miembros en menos de nueve meses". Por lo tanto, este medio al ser tan influyente es una bondadosa herramienta para establecer medio de contacto directo (sin intermediarios) con los clientes.

Fonseca (2014:4) defines las redes sociales como "la evolución de las tradicionales maneras de comunicación del ser humano, que han avanzado con el uso de nuevos canales y herramientas, y que se basan en la creación, conocimiento colectivo y confianza generalizada". Por lo tanto, la atención al cliente se ha hecho una práctica muy común a través de las redes sociales, como herramienta complemento de marketing en el impulso de las ventas.

En este sentido, las redes sociales de la mano de los avances tecnológicos se han encargado de transformar la manera de comunicarse, concibiendo nuevos canales de comunicación, en los cuales la retroalimentación o feedback ha sido elemento fundamental, de esta manera las empresas han sabido aprovechar todas estas herramientas para construir una cercanía con el cliente y que este se sienta bien atendido, impulsando así a que por medio de estos estímulos emocionales se sienta bien atendido y considere un valor agregado hacia el bien o servicio ofrecido.

Uno de los medios que se ha popularizado como manera de comunicación tanto personal como comercial es la plataforma de WhatsApp, la cual nació como una aplicación de mensajería en el 2009, desde la fecha de su lanzamiento a la actualidad ha experimentado innumerables actualizaciones, las mismas han ofrecido a los 
usuarios otras maneras de interactuar, hasta ser catalogado como una red social, tal como lo comenta Ramos (2015:5) "WhatsApp no es solo un programa de mensajería instantánea, sino que también podemos considerarla como una autentica red social, ofreciendo un interesante conjunto de características que incluyen la creación de grupos y el envío de imágenes, audio y video".

Por tal motivo, una de las empresas que utiliza el WhatsApp como medio para interactuar con los clientes es Mundo Geylin C.A., dedicada a la comercialización de piezas y componentes de bisutería para la fabricación de accesorios como pulseras, collares, brazaletes, zarcillos, entre otros. Así mismo, venta de herramientas necesarias para el proceso de realización de los accesorios antes mencionados, tales como, pinza entorchado, pinza redonda, pinza de silicón, entre otros.

Este establecimiento además de tener un espacio físico en el Pasaje Centro, local 13, Valencia estado Carabobo, Venezuela, también coloca sus productos en el mercado a través de la plataforma tecnológica Mercado Libre y de la red social Instagram, mediante las cuales se puede acceder y obtener información acerca del producto que ofrecen, precios, ubicación del establecimiento, teléfonos de contacto, tanto móvil como fijo, a través de esa plataforma se tiene acceso a una canal de comunicación vía WhatsApp, mediante el mismo se tiene acceso a una conversación directa con el personal de atención al cliente del establecimiento, por medio del cual se pueden hacer consultas, despejar dudas, realizar pedidos, solicitar cotizaciones, información sobre pedidos enviados, promociones, ofertas y cualquier duda o comentario que desee realizar el cliente.

De tal manera, que la responsabilidad de administrar estas plataformas recae sobre una persona, empleado del establecimiento, dentro de sus funciones principales está la actualización de los productos, precios y atención a los pedidos y dudas que tengan los clientes. Se ha presenciado que en los últimos meses ha incrementado notablemente la afluencia de interacción a través de este espacio, mayormente de personas que realizan consultas de precios, a pesar de esto ha habido disminución en las ventas. El incremento en la afluencia de interacción con los clientes ha tenido como consecuencia aumento en los tiempos de respuesta a razón de que la misma persona que se ocupa de la actividad en WhatsApp de igual manera tiene la responsabilidad de atender a los clientes que requieren atención a través del portal electrónico de ventas masivas, mercado libre y la atención de los clientes en su espacio físico ubicado en la dirección antes mencionada.

El aumento en el tiempo de respuesta vía la aplicación WhatsApp podría desembocar en sensación de desinterés de los clientes con respecto a la relación de venta, es decir, el cliente al no recibir respuesta rápida y oportuna puede concluir en que la empresa no tiene intención de venderle, esta situación haría que el cliente busque otras alternativas, por lo consecuente existiría disminución de 
los clientes, esto resultaría a su vez en un descenso de las oportunidades de venta.

Por las consideraciones nombradas anteriormente, se debe comentar que se han suscitado problemas en el despacho de la mercancía, por ejemplo, intercambio de pedidos al momento del despacho, es decir, envíos a destinos equivocados, lo que el cliente podría interpretar de manera poco beneficiosa y generar desconfianza. Al mismo tiempo se generaría exceso de trabajo en el empleado encargado, lo que resultaría en actitud hostil hacia el cliente.

De acuerdo con todo lo antes mencionado, se puede afirman que en Mundo Geylin, C.A. no cuentan con políticas o lineamientos generales con respecto al comportamiento de los clientes, por lo tanto, se desconoce el nivel de satisfacción de los clientes y cumplimiento de las expectativas de los mismos.

\section{MATERIALES Y MÉTODOS}

La presente investigación fue documental, descriptiva y de campo y se inició con la observación directa participante, durante la cual se visualizó la existencia de situación irregular, la cual generó un problema, por lo tanto, el diseño fue no experimental por ser analítico de la situación y no generó interés alguno en modificar la realidad para realizar el estudio.

El colectivo investigado estuvo conformado por los clientes que efectivamente realizaron alguna compra a través de la plataforma de mensajería instantánea WhatsApp de la empresa Mundo
Geylin C.A., durante los últimos tres (3) meses en el periodo de estudio (2019), conformada por veintiocho (28) personas.

Los datos fueron extraídos de la cuenta de WhatsApp utilizada como medio para el servicio de atención al cliente. Dada la naturaleza de esta investigación y de acuerdo con los datos requeridos, se utilizó como técnica el cuestionario.

\section{RESULTADOS Y DISCUSIÓN}

En esta sección se presentan algunos elementos teóricos que se consideran fundamentales para la comprensión del tema investigado. El primero de estos temas es el relacionado con el marketing. Dvoskin (2004:21) define al marketing como "una disciplina de la Ciencia Económica cuyo objetivo es potenciar las capacidades de las organizaciones $y / o$ individuos oferentes de bienes o servicios que, insatisfechos con una situación competitiva, aspiran a pasar a otra más ventajosa"

De igual forma Kotler (2003:4) describe al marketing en el ámbito social como "un proceso a través del cual los individuos y grupos obtienen lo que necesitan y lo que desean mediante la creación, la oferta y el libre intercambio de productos y servicios valiosos con otros" En este sentido, implícitamente se puede notar que, en las dos definiciones referidas anteriormente, se señala una relación entre ellas de manera de conducir a un producto de una situación a otra, es decir, hacer que este sea o parezca ser de mayor provecho para los consumidores, de tal manera que lo 
adquieran. Asimismo, la atención al cliente pretende consolidar la fidelización de los clientes, de tal manera llegar a lograr a adquieran los productos dada la fidelización que tengan hacia el mismo.

Otro elemento importante de reseñar es el Plan de Servicio al cliente. Para brindar un servicio excepcional, la empresa debe desarrollar un plan de servicio al cliente y no improvisarlo como se hace en la gran mayoría de las ocasiones. Para esto, existen cuatro pasos básicos y sencillos que pueden aplicarse en cualquier empresa (por más pequeña que esta sea) y que se deben considerar para poder materializar un plan de servicio exitoso, que conforme parte de una estrategia diferenciadora en el mercado. A continuación, se definen los pasos:

- Diagnóstico para medir las percepciones: Lo primero que debe hacerse en una pequeña investigación de mercado para conocer los niveles de satisfacción de los clientes con respecto a nuestros servicios.

- Establecer la filosofía de la empresa: objetivos enfocados en servicio y la creación de políticas y garantías para el cliente. La empresa debe identificar un camino a seguir para tratar con el cliente.

- Implementación del plan: Para este paso, primero se debe capacitar a todo el personal. Todos deberían conocer las políticas de servicio que se brindarán a favor del cliente. No se puede implementar el plan si todo el personal no comprende a la perfección la nueva filosofía de servicio. Además, deben de comunicarse las nuevas políticas de servicio a los clientes externos.

- Desarrollo de mecanismos de control y seguimiento: Hay que establecer indicadores que permitan medir la mejora de las percepción de los clientes y su satisfacción con respecto a nuestros servicios y productos, indicadores que detallen el aumento en la recompra y la disminución de la periodicidad de compra de los clientes actuales, la generación de nuevos clientes por referidos $y$ recomendaciones, establecer la periodicidad con la que se encuestarán a estos consumidores para conocer los cambios de sus percepciones y establecer la calendarización anual de capacitaciones en servicio al cliente para el personal, entre otros.

Es necesario cumplir los pasos antes mencionados, ya que de su cumplimiento dependerá el éxito o fracaso de la implementación del plan realizado previamente, de igual manera se debe proceder contemplando el cumplimiento de cada una de las etapas.

En relación con lo antes mencionado se debe de igual manera comentar la definición de atención al cliente, para entrar en contexto sobre el tema propósito de estudio. De tal manera, Pérez Torres (2006:6) define atención al cliente como "el conjunto de prestaciones que el cliente espera como consecuencia de la imagen, el precio y la reputación del producto o servicio que recibe." Plantea el autor los elementos claves 
en la organización de la atención al cliente, los mismos se detallan a continuación:

El ciclo del servicio: es la secuencia de acontecimientos repetidos durante la prestación del servicio, en la cual diferentes personas intentan satisfacer las necesidades y expectativas del cliente en cada punto.

$\checkmark$ Los momentos críticos: en la prestación del servicio son aquellos momentos en que el cliente se pone en contacto con la empresa y se forma una opinión acerca de la calidad del servicio. (p.36)

El cliente al notar ciertas características del tipo de negocio que está buscando para cubrir sus necesidades, surge una expectativa de prestación de servicio, por lo que si no se cubren dichas expectativas el cliente puede sentirse insatisfecho y crear una opinión desfavorable sobre la compañía en la cual adquirió el producto.

Ariza y Ariza (2015:16) definen atención al cliente como "el conjunto de actuaciones mediante las cuales una empresa gestiona la relación con sus clientes actuales o potenciales, antes o después de la compra del producto, y cuyo fin último es lograr en él un nivel de satisfacción."

De esta manera diversas organizaciones consideran pertinente poseer un departamento o personal, dependiendo de la magnitud de la misma, únicamente dedicado a la atención al cliente, algunas de las funciones de dicho personal son: $\checkmark$ Atender y solucionar las solicitudes, sugerencias y reclamos de los clientes.

$\checkmark$ Obtener y gestionar la información derivada de la relación con los clientes, sobre todo en lo relativo a previsiones de ventas futuras.

$\checkmark$ Resolver cualquier incidencia relacionada con el servicio posventa, como garantías, devoluciones, reparaciones O sustituciones.

Por otra parte, es necesario mencionar que tanto Ariza y Ariza como Pérez Torres mencionan la satisfacción del cliente, lo cual es clave para lograr la fidelización de los mismos, lo que posiblemente derive en opiniones positivas de los clientes sobre la compañía, de tal manera se pueda lograr captación de otros clientes.

Además de lo antes mencionado, algunos autores lo definen como servicio de atención al cliente, tal es el caso de Paz Couso (2005:1) quien explica que servicio atención al cliente son "todas las actividades que ligan a la empresa con sus clientes", de tal manera que toda actividad $y$ comunicación que tenga cualquier empleado con algún cliente de la empresa se puede definir como atención al cliente, por lo que estás actividades son de suma importancia para la compañía ya que si la actividad no está enfocada a los clientes no tiene sentido realizarla. De tal forma, dentro de las actividades antes mencionadas se encuentran las indicadas a continuación: 
Actividades necesarias para asegurar que el producto/servicio se entrega al cliente en tiempo, unidades y presentación adecuados.

$\checkmark$ Relaciones interpersonales establecidas entre la empresa y el cliente.

$\checkmark$ Servicios de reparación, asistencia y mantenimiento postventa.

$\checkmark$ Servicio de atención, información y reclamaciones de clientes.

$\checkmark$ Departamento de recepción de pedidos de la empresa.

Por otra parte, de acuerdo con la definición de atención al cliente y servicio de atención al cliente, se puede afirmar que ambas definiciones son semejantes, ya que ambas hacen referencia a relación entre empresa - cliente, la cual es fundamental para el desarrollo y crecimiento de una empresa.

En otro orden de ideas, para lograr la efectividad de todas las actividades antes nombradas se requiere tener una buena comunicación con el cliente. Dentro de este marco de ideas Paz Couso (2005:8) define a la comunicación como "la transmisión de información entre dos o más seres humanos; por información entendemos deseos, intenciones, decisiones u opiniones". De tal manera, la comunicación es de vital importancia en el proceso de atención al cliente ya que de una comunicación efectiva depende el conocer y entender las necesidades del cliente. De igual manera para llevar a cabo una dicha comunicación se debe tener en cuenta los elementos y las etapas de la comunicación.

\section{Elementos de la comunicación}

$\checkmark$ Emisor y receptor: El emisor es el sujeto que comunica en primer lugar o toma la iniciativa de ese acto de comunicación, mientras que el receptor es el que recibe el mensaje.

$\checkmark$ El mensaje: Conjunto de diferentes ideas o informaciones que se trasmiten mediante códigos, claves, imágenes.

$\checkmark$ El código: Es el conjunto de claves imágenes, lenguaje, normas. Que sirven para transmitir información.

$\checkmark$ El canal: Es el medio a través del cual se emite el mensaje del emisor al receptor.

$\checkmark$ El contexto: Es la situación concreta en la que se desarrolla la comunicación.

$\checkmark$ El feedback o retroalimentación: Es la información que devuelve el receptor al emisor sobre su propia comunicación.

Dentro del proceso de comunicación es necesario conocer cada uno de sus elementos ya que de ello dependerá que el mensaje sea recibido y produzca el impacto deseado.

\section{Etapas de la comunicación}

Voluntad de comunicarse.

$\checkmark$ Emisión del mensaje

$\checkmark$ Recepción del mensaje

$\checkmark$ Comprobación de la comprensión del mensaje 
Con respecto a las etapas de la comunicación expresadas anteriormente, se puede afirmar que la de mayor envergadura es la última, ya que de la comprobación del mensaje depende el hecho de conocer que el mensaje enviado llego de la manera deseada e interpretado del mismo modo que fue enviado.

De igual forma Paz Couso (2005:18) comenta que "Ruido es todo elemento que entorpece el proceso de comunicación, pudiendo incluso, llegar a anularlo." Es conveniente comprender la envergadura que adquiere el ruido en dicho concepto por lo que puede interrumpir de tal manera la comunicación y llegar a anularla, la anulación de la comunicación podría conllevar a dificultades para retomarla la misma. En este sentido primordiales formas de ruido son:

$\checkmark \quad$ No compartir el mismo lenguaje.

$\checkmark$ Falta de voluntad de comunicarse.

$\checkmark$ La defensividad.

$\checkmark$ El conocimiento insuficiente de los productos o servicios.

$\checkmark$ La incapacidad para escuchar.

$\checkmark$ El entorno.

Otro tema de gran relevancia es el cliente. Pérez Torres (2006:3) plantea que "Es necesario resaltar la existencia y el papel desempeñado en la calidad de servicios por dos tipos principales de clientes, es decir, por los clientes externos y por los clientes internos". De tal manera que: $\checkmark$ Los clientes externos son aquellas personas que adquieren los productos $y$ servicios ofrecidos. Son extraños o ajenos a la empresa y son la fuente de ingresos que sostiene las operaciones

Los clientes internos son las personas que trabajan en la empresa y hacen posible la producción de bienes o servicios.

Es necesario hacer mención referente a los clientes internos y externos, ya que, con respecto a todo lo mencionado anteriormente el cliente interno realiza las funciones de servicio de atención al cliente externo, por lo que depende del cliente interno la satisfacción del cliente externo y posteriormente su fidelización.

Después de todo lo mencionado anteriormente se debe conocer el concepto de red social, la cual Fonseca (2014:1) define como "la evolución de las tradicionales maneras de comunicación del ser humano, que han avanzado con el uso de nuevos canales y herramientas y que se basan en la creación, conocimiento colectivo y confianza generalizada."

Las redes sociales conservan el proceso de la comunicación, sin embargo, como consecuencia de los avances tecnológicos surgen nuevos canales de comunicación como lo son los teléfonos inteligentes con aplicaciones en las cuales puedes enviar mensajes de voz, video mensajes, entre otros. Existen muchos tipos de redes sociales, entre las que se pueden caracterizar: 
$\checkmark$ Redes sociales generalistas: Aquellas en las que participa todo tipo de público. Algunas redes están más orientadas a compartir información y contenidos, y en otros casos simplemente a comunicar.

$\checkmark$ Redes sociales verticales: Son aquellas redes con temáticas que surgen para crear una comunidad de usuarios que comparten intereses.

$\checkmark$ Redes para la difusión de un tipo de contenido: Se utilizan para publicar y compartir fotos, video, música, links o noticias.

Con respecto a los tipos de redes sociales expresadas anteriormente, se debe comentar que primero se debe conocer en qué tipo de red social se va a incursionar, de tal manera conocer si está orientada a las necesidades del usuario.

\section{Principios básicos para participar en las redes sociales \\ $\checkmark$ Escuchar. \\ $\checkmark$ Participar e involucrarse con tu audiencia}

$\checkmark$ Medir los resultados de participación en las redes sociales

$\checkmark$ Integrar las redes sociales en los procesos de la empresa

$\checkmark$ Colaborar y compartir

$\checkmark$ Ayudar

Por último, es necesario comprender los principios básicos para participar en las redes sociales, puesto que de ellos derivará el logro de los objetivos de su aplicación o uso dentro de las actividades de la empresa.

\section{Resultados del cuestionario}

A continuación, se presentan los resultados del cuestionario, el mismo fue aplicado a veintiocho (28) clientes que efectivamente realizaron alguna compra, segregados en los meses octubre, noviembre y diciembre del año dos mil diecinueve (2019). 


\section{Gráfico $\mathbf{N}^{\circ} 1$}

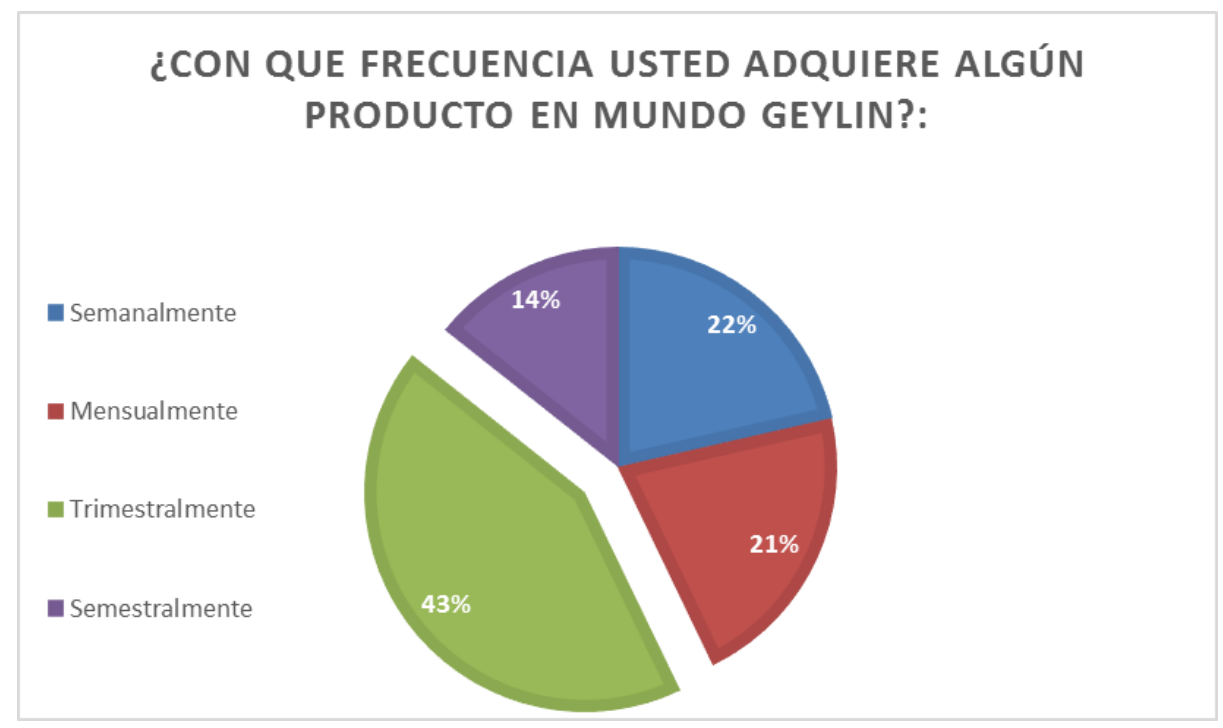

Fuente: Amate A. (2019)

Tal como puede observarse, el cuarenta y tres por ciento (43\%) de los clientes adquieren algún producto de manera trimestral, esto denota la importancia de tener un buen servicio prestado a los clientes, ya que la mayoría de ellos sólo compran cada tres (3) meses, por lo mismo se debe estar seguro que los clientes que se atiendan tengan un alto nivel de satisfacción para así, luego de tres meses (3) de su última adquisición, cuando les surja la necesidad de adquirir uno de los productos de los ofrecidos por Mundo Geylin CA, que estos sean su primera opción.

\section{Gráfico $\mathbf{N}^{\circ} 2$}

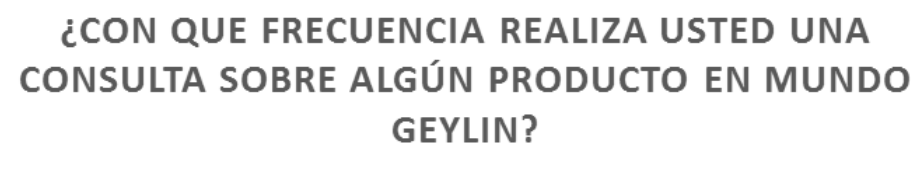

-Semanalmente Mensualmente $\quad$ Trimestralmente Semestralmente

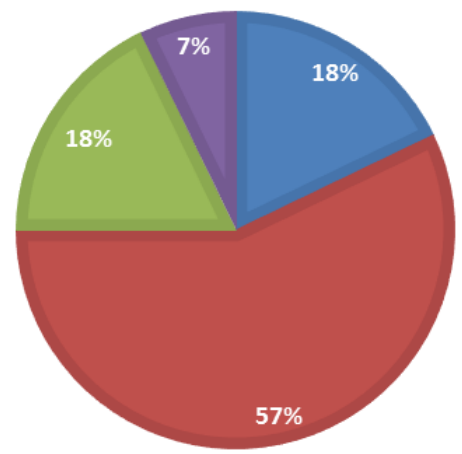

Fuente: Amate A. (2019) 
En virtud de lo que se observa en el gráfico, el cincuenta y siete por ciento (57\%) de los clientes encuestados realizando alguna consulta sobre algún producto de manera mensual, esa situación denota una oportunidad cada mes de interactuar con el cliente y conocer cuáles son sus necesidades actuales, su nivel de satisfacción, conocer su opinión en general, de tal manera tener información primaria para evaluar el proceso de servicio de atención al cliente de la organización.

\section{Gráfico $\mathbf{N}^{\circ} 3$}

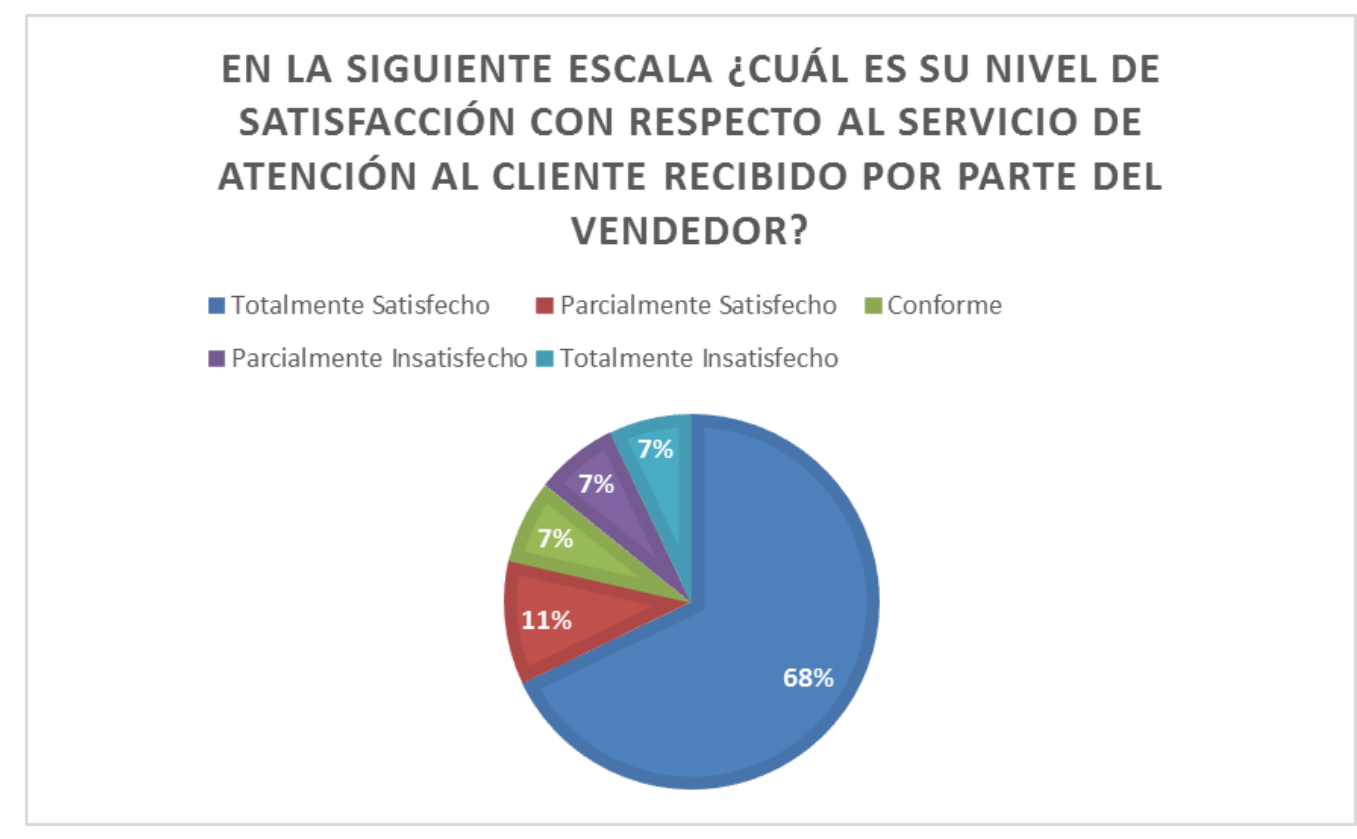

Fuente: Amate A. (2019)

Como se evidencia en el Gráfico arriba reflejado, el sesenta y ocho por ciento (68\%) de los clientes que se atienden a través de WhatsApp se sienten muy satisfechos, el resto de los clientes encuestados están divididos entre parcialmente satisfecho, conforme, parcialmente insatisfecho y totalmente insatisfecho. En base a los resultados de esta pregunta en específico, se puede inferir que el treinta y dos (32\%) de los clientes encuestados identifican por lo menos una oportunidad de mejora en el proceso de servicio de atención al cliente prestado por el empleado de Mundo Geylin, CA.
De tal manera Ariza y Ariza (2015:16) mediante su concepto de atención al cliente como "el conjunto de actuaciones mediante las cuales una empresa gestiona la relación con sus clientes actuales o potenciales, antes o después de la compra del producto, y cuyo fin último es lograr en él un nivel de satisfacción."; menciona que el propósito de la atención al cliente es el nivel de satisfacción del mismo por lo que se debería conocer la opinión de los clientes que no están totalmente satisfechos y tomarla en cuenta para tomar decisiones en cuanto la atención prestada. 


\section{Gráfico $\mathbf{N}^{\circ} 4$}

\section{¿CÓMO CONSIDERA USTED EL TIEMPO QUE TARDA}

EL EMPLEADO EN ATENDER SUS

REQUERIMIENTOS?

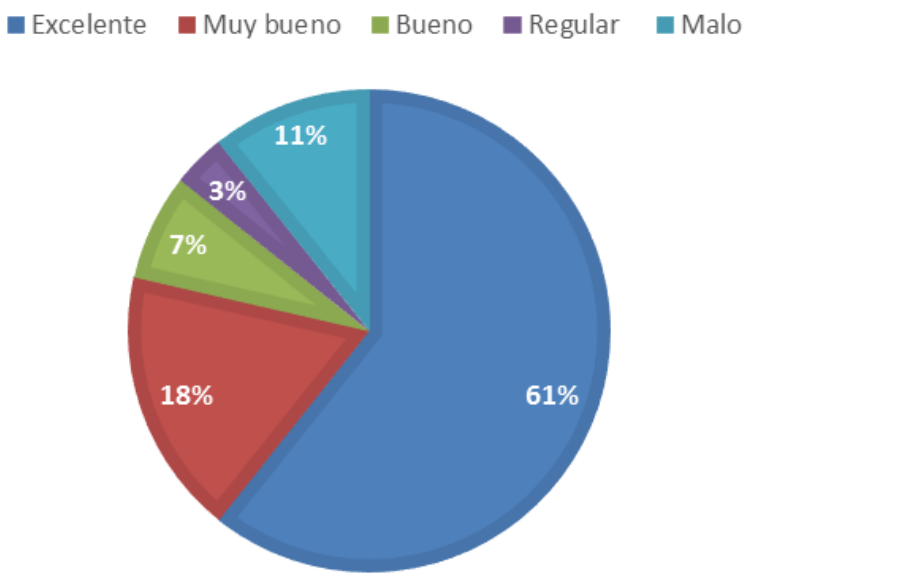

Fuente: Amate A. (2019)

Tal como se puede observar en la gráfica, un sesenta y un por ciento (61\%) de los clientes encuestados consideran que el tiempo que tarda el empleado en responder a sus requerimientos vía WhatsApp es excelente, sin embargo, el treinta y nueve por ciento (39\%) restante los encuestado lo consideraron en escalas entre muy bueno, bueno, regular y malo, teniendo diferentes ponderaciones cada uno de estas opciones.
Dichos datos son de gran utilidad, ya que en el tiempo que tarde en responder el empleado a los requerimientos de los clientes dependerá el interés sienta el cliente que el empleado tiene hacia él, de igual manera puede que el cliente en ese lapso de tiempo consiga otro establecimiento en el cual pueda obtener el mismo producto $y$ sienta satisfecho con el servicio al cliente prestado. 


\section{Gráfico $N^{\circ} 5$}

\section{¿CUÁL CONSIDERA USTED UNA OPORTUNIDAD DE MEJORA EN EL SERVICIO AL CLIENTE?}

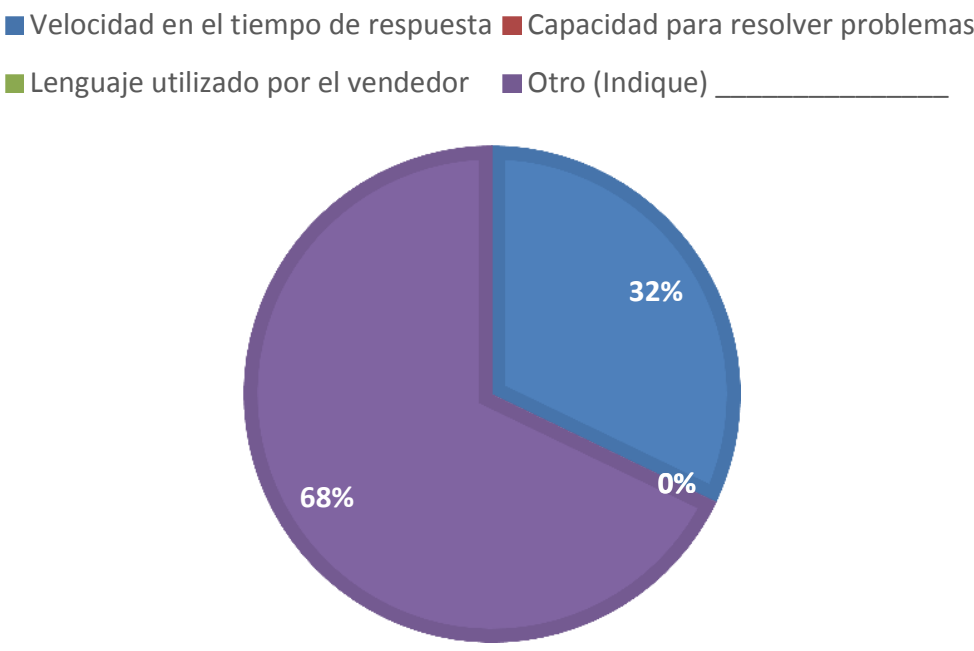

Fuente: Amate A. (2019)

Del total de los cliente encuestados, según la gráfica se puede afirmar que el treinta y dos por ciento (32\%) de ellos considera que la velocidad en el tiempo de respuesta es una oportunidad de mejora, es decir, que consideran que el tiempo que tardan en responder sus solicitudes vía WhatsApp es muy lento, por otro lado, el sesenta y ocho por ciento (68\%) de los clientes encuestados consideran que no existe alguna oportunidad de mejora, considerando así que el servicio de atención al cliente prestado es excelente, por lo que se sienten muy satisfechos, tal como se puede visualizar en la gráfica $\mathrm{N}^{\circ} 3$. 


\section{Gráfico $\mathbf{N}^{\circ} 6$}

\section{DE ACUERDO CON EL SERVICIO RECIBIDO \\ DURANTE SU COMPRA, ¿VOLVERÍA A ADQUIRIR \\ UN PRODUCTO EN MUNDO GEYLIN?}

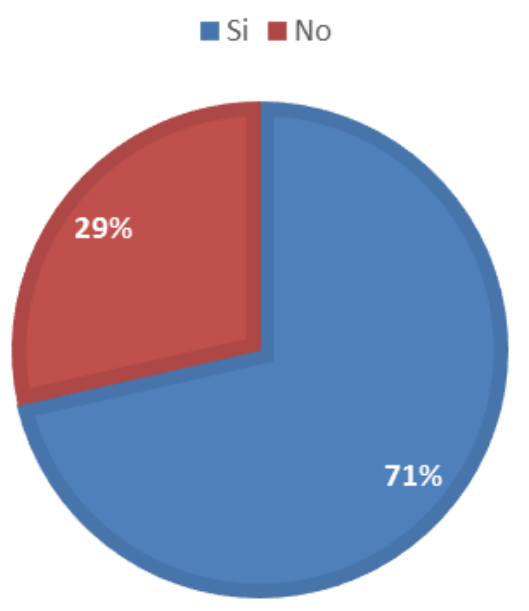

Fuente: Amate A. (2019)

Como resultado del Gráfico $N^{\circ}$ 6, se puede afirmar que el setenta y un por ciento (71\%) de los encuestados podrían volver a adquirir algún producto en Mundo Geylin C.A., mientras que el veintinueve por ciento (29\%) restante definitivamente no adquirirá producto alguno, de tal manera existen oportunidades de mejora en las actividades que ligan a la empresa con sus clientes, tal como lo comenta Paz Couso (2005:1) que expresa que atención al cliente son "todas las actividades que ligan a la empresa con sus clientes", por lo tanto, se deben evaluar las diferentes actividades y la comunicación empresa - cliente con la finalidad de detectar dichas oportunidades de mejora.

Por otra parte, el que un cliente no adquiera nuevamente algún producto trae como consecuencia pérdida de clientes, además puede producir referencias negativas de aquellos clientes que consideran no volverán a adquirir algún producto hacia aquellas personas que se encuentran en su círculo social. 


\section{Gráfico $\mathbf{N}^{\circ} 7$}

¿CONSIDERA USTED QUE EL USO DE WHATSAPP PARA

ATENDER LOS REQUERIMIENTOS DE LOS CLIENTES ES SUFICIENTE?

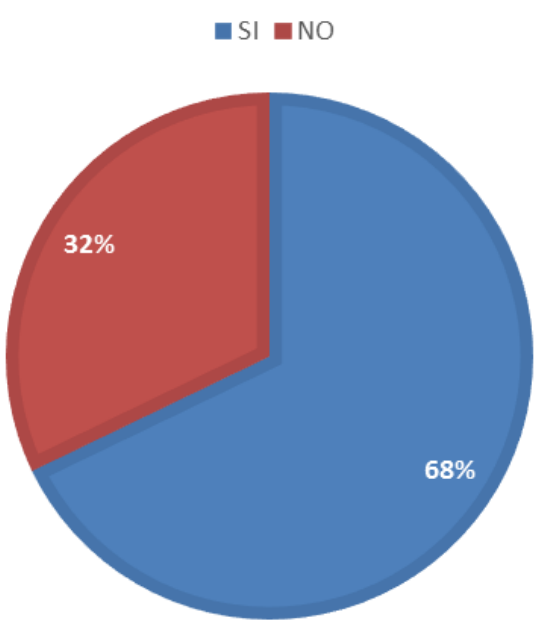

Fuente: Amate A. (2019)

Del total de clientes encuestados el sesenta y ocho por ciento (68\%) afirma que es suficiente la vía de WhatsApp como único canal de comunicación con los clientes, sin embargo el treinta y dos por ciento (32\%) restante afirma que no es suficiente, por lo que se puede afirmar que existen otros canales de comunicación que no se están aprovechando para que los clientes tengas varias opciones para comunicarse con el personal de Mundo Geylin, C.A. ya que posiblemente no todos los clientes potenciales tengan disponibilidad de la plataforma de mensajería instantánea WhatsApp como canal de comunicación, por lo que debería evaluarse alternativas de emplear otros canales de comunicación a fin de poseer varias opciones de comunicación con el cliente. 


\section{Gráfico $\mathbf{N}^{\circ} 8$}

\section{¿EN CUAL DE LAS SIGUIENTES REDES SOCIALES USTED TIENE MAYOR ACTIVIDAD?}

— Facebook

- Twitter

- Instagram

- Linkedln

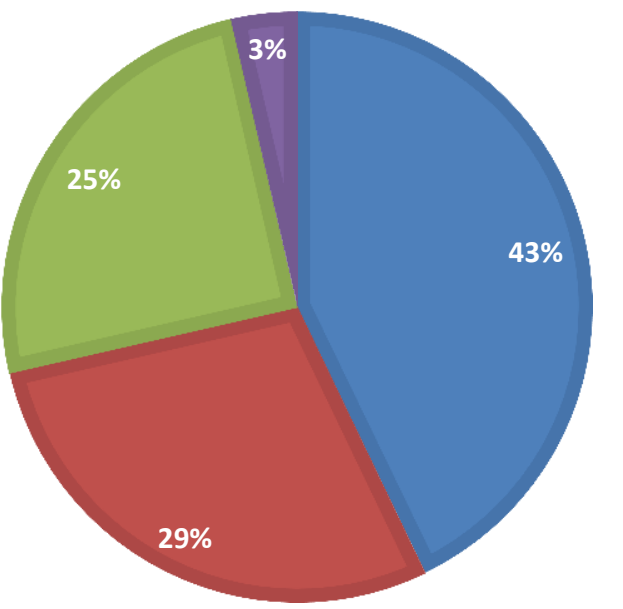

Fuente: Amate A. (2019)

Tal como se puede observar en la gráfica, el cuarenta y tres por ciento (43\%) de los clientes encuestados utilizan más Facebook que otras redes sociales, el veintinueve por ciento $(29 \%)$ utiliza twitter, un veinticinco por ciento (25\%) Instagram y el resto LinkedIn, de tal forma como comenta A Fonseca (2014:1) que las redes sociales son "la evolución de las tradicionales maneras de comunicación del ser humano, que han avanzado con el uso de nuevos canales y herramientas" bajo este contexto se contempla una oportunidad, ya que se puede hacer uso de las otras redes sociales con la finalidad de cubrir el mayor número de canales de comunicación que utilicen nuestros clientes, de tal manera, poder cumplir con sus expectativas y crear mayores niveles de confianza. 


\section{Gráfico $\mathbf{N}^{\circ} 9$}

\section{¿CUÁL ES LA CALIDAD USTED CONSIDERA QUE POSEEN LOS PRODUCTOS OFRECIDOS POR MUNDO GEYLIN C.A.? \\ Excelente Muybueno Bueno $\square$ Regular $\square$ Malo}

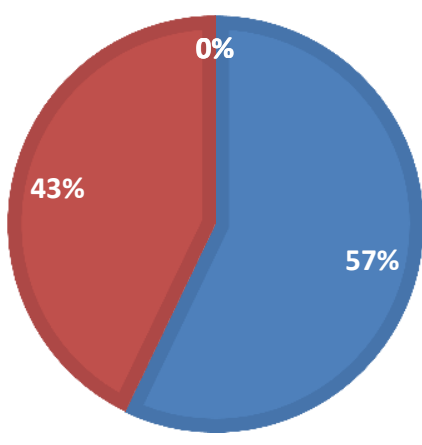

Fuente: Amate A. (2019)

Tal como se puede visualizar en el gráfico el total de los clientes encuestados considera que los productos comercializados por Mundo Geylin C.A gozan de una característica entre excelente y muy buena calidad, por lo que se puede afirmar que los productos que se puede afirmar que dada a la calidad de los productos que ofrece Mundo Geylin C.A. se puede considerar este aspecto como una fortaleza.

\section{Gráfico $\mathbf{N}^{\circ} 10$}

\section{¿ANTERIORMENTE SE LE HABÍA REALIZADO ALGUNA PREGUNTA O CONSULTA SOBRE LA ATENCIÓN RECIBIDA EN MUNDO GEYLIN C.A.?}

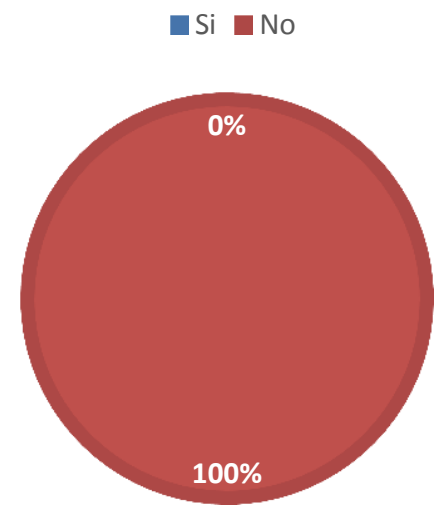

Fuente: Amate A. (2019) 
Para concluir la encuesta, se realiza una pregunta muy importante, mediante la cual se obtiene como resultado que el cien por ciento (100\%) de los clientes encuestados jamás se le había realizado alguna pregunta sobre su nivel de satisfacción a razón de la atención al cliente recibida, por lo tanto a nivel gerencial Mundo Geylin C.A. desconocía si los clientes se sentían a gusto durante la adquisición de algún producto, por lo que de igual manera desconocía la razón de cualquier comportamiento del cliente.

Como resultado de la encuesta empleada se pudo conocer que en porcentaje mayor los clientes realizan compras trimestrales y consultas de precios y productor de manera mensual. De igual manera el porcentaje más alto de los clientes se sienten totalmente satisfechos, sin embargo, existe un porcentaje de clientes que no se sienten totalmente satisfechos, por ende, estos detectan oportunidades de mejora en el servicio de atención al cliente. Uno de los aspectos que se evaluó en el cuestionario es el tiempo que tarda el empleado en atender los requerimientos de los clientes, dando como resultado que a poco más de la mitad le parece que es excelente, el resto lo clasifico entre muy bueno, bueno, regular y malo por lo que sería un aspecto que está repercutiendo en la satisfacción que tienen los clientes.

La minoría de los clientes expresaron que no volverían a adquirir algún producto, dado que el servicio de atención al cliente no cumplió con sus expectativas. Por otra parte, menos de la mitad de los encuestados considera que el uso de WhatsApp como única vía para atender a los clientes es insuficiente, por lo mismo se deben evaluar otros canales de comunicación a través de redes sociales, tales como, Facebook, Twitter y LinkedIn, para abarcar aquellos clientes que no solo utilizan WhatsApp e Instagram.

Finalmente, se conoce que no se había realizado antes alguna pregunta a los clientes sobre su nivel de satisfacción y las opiniones que ellos podrían suministrar sobre el proceso empleado para atenderles, por lo que se desconocía el motivo por el cual algunos no habían adquirido nuevamente algún producto de los que ofrece Mundo Geylin. C.A.

\section{CONCLUSIONES}

La investigación realizada refleja la importancia del uso de las redes sociales como estrategia de marketing y ventas en los tiempos globales, siendo la atención al cliente un elemento clave dentro del proceso de sostenibilidad de la empresa en el mercado y su posicionamiento.

Por esta razón, las empresas deben contar con eficientes servicios de atención al cliente manejados por un personal capacitado, lo cual posee grandes ventajas como bajos costos, genera mayor oportunidad de captación de clientes, permite atender las reales necesidades de los clientes y así lograr un alto nivel de satisfacción de los mismos. 
Las redes sociales poseen millones de usuarios alrededor del mundo, en Venezuela las más usadas son Facebook, Instagram y Twitter. Al participar un amplio número de personas en ellas las organizaciones tienen una oportunidad para estar cerca del cliente y su red, saber sus preferencias y en básicamente conocer su satisfacción con el producto ofrecido.

\section{REFERENCIAS}

Aced, Cristina (2010). Redes sociales en una semana. Ediciones gestión 2000. España

Ariza R, Francisco J, y Ariza R, Juan M. (2015). Información $y$ atención al cliente. McGraw Hill Education. Disponible en http://assets.mheducation.es/bcv/guide/c apitulo/8448196813.pdf. Consulta: 23 de octubre de 2017

Carrasco, S. (2012). Atención al cliente en el proceso comercial. Ediciones paraninfo, S.A. España

Dvoskin, (2004). Fundamentos de Marketing Teoría y experiencia. Ediciones Granica S.A. Buenos Aires. Argentina
Fonseca, Alexandre S. (2014). Marketing Digital en Redes Sociales. Disponible en https://books.google.co.ve/books?id=ibB EBAAAQBAJ\&pg $=P T 22 \& d q=$ redes + social es+definicion $\& \mathrm{hl}=\mathrm{es}-$

419\&sa $=$ X\&ved $=0$ ahUKEwi7yLjEOuvZAh WFuRQKHXgrACEQ6AEIQTAE\#v=onepag e\&q=redes\%20sociales\%20definicion $\& f=$ false. Consulta: 14 de marzo de 2018.

Kotler P, (2003). Dirección de marketing: Conceptos Esenciales. Pearson Hall. México

Paz Couso, Renata (2005). Servicio al cliente. La Comunicación y la Calidad del Servicio en la atención al cliente. Ideaspropias editorial. España

Pérez T, Vanesa $S$, (2006). Calidad total en la atención al cliente, pautas para garantizar la excelencia en el servicio. lera edición. Ideaspropias editorial. España

Ramos Juanjo (2015). Marketing con WhatsApp. Guía practica. GD Publishing Ltd. \& Co. KG. Berlin, Alemania 